logically as the second. The world of those born blind is just as spatial as the world of the sighted but in a phenomenologically different way. In haptic space we proceed from structure to form; in visual space we proceed from form to structure. Apprehension of form means the appreciation of a unity of elements fused in a total impression. Apprehension of structure means consciously acquiring knowledge of the spatial and temporal relations of the perceived object. Prof. Révész derives a number of principles which he believes govern haptic perception in a distinctive way.

Much of the second part of the book is taken up with a careful study of the life-histories and artistic achievements of a number of blind sculptors. Here one must pay a tribute to the immense effort expended by the author in collecting and checking his data. He concludes that the resthetic 'function' of the haptic sense is very limited. The blind are unable to apprehend objects as individual entities because haptic perception merely gives type images devoid of individuality. This may explain why they have no desire to finger objects of art or to learn details of their form and structure.

The foregoing indicates the kind of issue raised by Prof. Révész. The reader interested in almost any aspect of human perception or in the nature of æsthetic experience is bound to learn a great deal from his book. He had also better prepare himself to unlearn, because he will encounter a challenge to many of his preconceptions. JOHN COHEN

\section{TEXT-BOOK OF SILVICULTURAL SYSTEMS}

Silvicultural Systems

By Dr. R. S. 'I'roup. (Oxford Manuals of Forestry.) Second edition, edited by E. W. Jones. Pp. xv+ $216+43$ plates. (Oxford: Clarendon Press ; London : Oxford University Press, 1952.) 25s. net.

$\mathrm{T}$ ROUP'S "Silvicultural Systems", published in 1928, has long been recognized both as one of the best forestry text-books in the English language and the best survey in any language of the subject with which it deals. Changes in the methods of handling forests, however desirable, can only be a very slow process, as variation in future treatment is unavoidably largely circumscribed by what has been done in the past. A consequence of this fact is that although changed practices inevitably become necessary with increase of experience and the progress of knowledge, a book such as this does not quickly become out of date. It is therefore not surprising that even after twenty-four years the editor of the new edition finds that he can accept almost unchanged the greater part of the text, and that, apart from a few relatively minor amendments, changes in view and in practice can mostly be dealt with in an additional final chapter. Dr. E. W. Jones has among British foresters an unrivalled knowledge of the silviculture and silvicultural practices of western Europe, derived from repeated visits, particularly to France and Switzerland, and he has also first-hand knowledge of some of the silvicultural problems of tropical forests. As, also, he was on 'Troup's staff teaching silviculture and carrying out research in the position to bring Troup's book in line with current thought and practice.

In his preface, Dr. Jones enumerates the main changes he has made, and, except for modifying Troup's rather unqualified acceptance of the view that the selection system with all-aged crops gives timber inferior to that obtained with the more or less uniform (even-aged) crops, it is clear that his original contribution is concentrated in the new Chapter 20, "Developments of the Last Twenty Years". This is, indeed, a masterly and valuable summary of recent trends of thought in this field. Dr. Jones, man of science that he is, is very careful to keep in view the economic and practical considerations that must always play a large part in choosing between possible alternatives, and I only disagree with him in his reluctance to accept the view that supervision of uneven-aged forest is more difficult than that of more or less even-aged forests worked under the other systems ; above all, when the technical standard of the staff is not first-class.

This chapter brings out the greatly increased importance now attached to the maintenance of soil fertility, leading to a growing preference for less regularity both in age and size, and in species, and to the maintenance of the canopy, avoiding clear or very heavy fellings at all times. I miss at this point an assessment of the alleged merits of periodically admitting light and warmth to the soil, as there are certain conditions where the claim is made that undesirable accumulation of raw humus occurs without it; there are also conditions in the tropics where, with appropriate treatment, any damage that may ensue from such exposure may be more than compensated, both economically and silviculturally, by the quick establishment of a better new crop.

The second important point made is that there is now a demand for more freedom of action to adapt carrent work in the forest to economic changes, the nature and direction of which cannot be predicted. The feeling is very general that any operation which ties the hands of the forest manager for a long period is to be avoided : this is just one more of the reasons that is giving a bias in favour of woods of mixed ages and species. It might perhaps also have been noted how generally the stress has shifted from getting each area unit of a forest into a form fitting into a preconceived pattern under a silvicultural system, to getting it into a condition in which it is producing the maximum growth in quantity and quality. Attention is very rightly directed to the new factor of forest genetics to be kept in mind.

The five pages devoted to natural regeneration in tropical forests (pp. 200-4), together with p. 207 on the enrichment of tropical forest and scrub, while perhaps not entirely up to date, give a very fair idea of the position. 'I'he merits and demerits of clear felling with artificial regeneration, notably with agricultural crops ('taungya') as a method of quickly bringing a mainly unproductive forest into more or less full production, will appear to many to be of sufficient importance for fuller discussion; such drastic measures might quite well only be necessary once, when the forest is first brought under intensive working.

Dr. Jones has done forestry another considerable service in undertaking this revision, and it can confidently be predicted that the new edition will meet most requirements for another twenty years. 